\title{
O Controle Financeiro das Empresas Estatais
}

\section{Sebastião de Sant'Anna e Silva}

Professor universitário (Faculdade de Economia e Administração - UFRJ)

A imprensa tem registrado a preocupação do Tribunal de Contas da União com o problema do controle financeiro das empresas de que participa o Estado, empresas públicas e sociedades de economia mista. Ministros daquele Egrégio Tribunal, juristas e administradores têm-se manifestado, fazendo reparos e apresentando sugestões. Parece-nos, todavia, que a preocupação tem sido mais formal e jurídica, com a ilegalidade da não submissão das entidades aos sistemas de controle financeiro em vigor. Temos a impressão, porém, de que o assunto é mais complexo e de que aos aspectos jurídicos, embora relevantes, cumpre acrescentar outros talvez mais relevantes, de natureza econômica e administrativa.

A proliferação de empresas sob o controle, tutela ou com Moderno e resulta da sua feição profundamente intervencionista. Com a liquidação definitiva do "laissez-faire" e a assunção de responsabilidades econômicas pelo Estado, a Administração Pública viu-se obrigada a fazer modificações nos sistemas e instituições tradicionais, adequadas às funções clássicas do Governo. Ninguém discute que quando o Estado assume funções
industriais, comerciais, bancárias e outras da mesma natureza, não pode exercê-las com eficiência dentro dos princípios tradicionais da Administração Pública, instituídos para o desempenho dos deveres fundamentais que Adam Smith atribuía ao soberano: defender o país de agressões externas, manter a paz 
interna, distribuir a justiça e executar alguns serviços que, embora em princípio pudessem ser exercidos por particulares, não despertam seu interesse pelo vulto do capital exigido e baixa rentabilidade do investimento.

Um economista ${ }^{1}$ assim enumera as formas de gestão econômica de empresas pelo Estado:

1. Operação da empresa diretamente pelo Estado ou por autoridades territoriais, dentro da estrutura de suas outras atividades. Não há forma legal especial ou personalidade jurídica; as receitas e despesas, inclusive os investimentos, são incluídos no Orçamento Público.

2. Empresas públicas. O único proprietário é neste caso o Estado ou autoridades territoriais, mas a empresa tem a sua própria personalidade jurídica e é financeiramente independente, isto, é, suas receitas e despesas não passam pelo orçamento público.

3. Companhias do tipo misto, nas quais a autoridade pública possui a maioria das ações, mas o setor privado participa em maior ou menor extensão.

4. Companhias privadas de várias formas legais, nas quais o Estado ou outra autoridade pública pode ter uma participação acionária mínima".

Ao discutir as vantagens e desvantagens dessas diferentes modalidades de participação empresarial do Estado, o autor mencionado salienta, em resumo, o seguinte.

A operação direta de uma empresa industrial ou comercial por uma autoridade pública só se justifica quando é desejo do Estado subsidiar indiretamente ou de forma velada o custo de produção de determinada mercadoria ou serviço, seja para manter baixo os indices internos de preços seja para facilitar a competição nos mercados de exportação. Suas desvantagens são notórias e resultam do fato de não possuírem tais empresas autonomia legal ou financeira, sendo parte integrante da administração geral. Suas despesas e receitas são incluídas no orçamento geral e estão confundidas nos demais itens orçamentários da administração, o que torna impossivel realizar um

(1) HELLMUTH BERGMANN - "On the choice of forms of enterprise for industry for the processing of agricultural products in developing countries." Economics, Volume 6, Tübingen, Alemanha Ocidental. Embora o artigo se refira expressamente a empresas para a industrialização de produtos agricolas, suas consideraçōes de ordem geral são aplicáveis a empresas com outras finalidades. 
balanço do resultado de suas operações. Como conseqüência dessa falta de autonomia financeira e contábil, o capital necessário para a manutenção e expansão dessas empresas é quase sempre inadequado, e sua própria manutenção e conservação são deficientes. Outra grave falha na gestão de tais empresas é que ela é atribuída a funcionários que, embora possam ser tecnicamente competentes, não dispõem de experiência industrial ou comercial. Essas empresas encontram sérias dificuldades para o financiamento de suas operações, pois dependem inteiramente do orçamento público, o qual é uma fonte financeira bastante instável e duvidosa. Está fechado a elas o acesso ao mercado de capitais, porque os bancos e outras instituições de crédito raramente estão dispostos a financiar empresas inteiramente dependentes do orçamento público, inclusive para o pagamento das amortizações e juros dos empréstimos contraídos.

Para evitar os inconvenientes da operação direta de empresas industriais e comerciais pelo Estado, procura-se freqüentemente a constituição de empresas públicas independentes que, pelo menos em teoria, podem ser operadas de acordo com os princípios e métodos que rēgem a administração de empresas privadas. Como o capital dessas empresas pertence inteiramente ao Estado, este escolhe todos os seus dirigentes e administradores, o que é importante quando a finalidade política da empresa é relevante. De outro lado, como a contabilidade dessas empresas é separada do orçamento geral, podem elas apropriar reservas suficientes para reparos e reposições. Podem ainda recorrer não só aos fundos do orçamento geral para o seu financiamento como também ao mercado de capitais, tanto nacional como internacional. A gestão de tais empresas esbarra todavia com diversas dificuldades, decorrentes principalmente do fato de estarem sujeitos à supervisão de ministérios e departamentos da administração, assim como ao controle e auditoria dos organismos responsáveis pelo controle financeiro, orçamentário e contábil. Em conseqüência, essas empresas encontram dificuldades para a obtenção de decisões rápidas em assuntos vitais ou relevantes e não dispõem de flexibilidade para se adaptarem às mutaçōes da conjuntura econômica. Sofrem ainda freqüentemente as empresas públicas de ingerência política na escolha de seus dirígentes e ficam sujeitas a excesso de pessoal e ao mau recrutamento de seus empregados. Não são assim adequadas para atividades de natureza industrial e comercial fortemente influenciadas pelas con- 
dos seus produtos, sendo sua utilização mais aconselhada quando o objetivo político da empresa ou seu aspecto social é superior ao seu desempenho econômico.

As desvantagens dos dois tipos de empresa anteriormente mencionados têm ocasionado uma proliferação das denominadas sociedades de economia mista, ou seja sociedades de cujo capital participa o Estado como acionista majoritário, ao lado de acionistas particulares. Esse tipo de empresa assegura ao Estado a influência necessária na condução da atividade industrial ou comercial que lhe é atribuída, dada a posição majoritária do Poder Público na composição do capital, mas ao mesmo tempo permite que sejam levados em consideração os interesses do setor privado, uma vez que produtores e consumidores particulares podem subscrever ações do seu capital. Essa participação do setor privado nas empresas de economia mista faz com que sejam levados à sua gestão a experiência e os métodos de trabalho das empresas privadas congêneres. De outro lado, as sociedades de economia mista pode utilizar qualquer fonte de financiamento, pública ou privada. $O$ interesse do Estado na sua gestão faz com que esse canalize para elas, quando necessários, recursos orçamentários sob a forma de subsídios ou subvenções e financiamentos de instituições financeiras públicas. Paralelamente, sua gestão independente, igual à de uma empresa privada, possibilita o seu acesso a qualquer instituição do mercado de capitais, interno ou internacional. A crítica feita a esse tipo de empresa é que os favores que a mesma freqüentemente recebe do Estado, sob a forma de um monopólio, de uma subvenção, de subsídio ou de isenções fiscais, revertem também em favor de seus acionistas privados. Pode-se responder à crítica dizendo que as vantagens e favores concedidos pelo Estado às empresas de economia mista correspondem à sua participação majoritária no capital e se justificam pelo motivo de interesse público que tenha determinado a constituição da empresa. De outro lado, a abertura de seu capital ao público e a negociação de suas ações na Bolsa tornam essas vantagens democraticamente acessíveis a todos, tirando-lhes qualquer caráter de privilégio injustificável.

A empresa privada é geralmente reconhecida como mais eficiente para a condução de atividades comerciais e industriais. O inconveniente é que elas, como é natural, maximizam os lucros e resultados a curto prazo, não se interessando pela promoção do desenvolvimento econômico do país a longo prazo. Para corrigir essa distorção, pode o Estado, sob a modalidade 
de participação acionária minoritária, estimular a empresa privada para que se preocupe com o desenvolvimento econômico a longo prazo. Seria assim a participação acionária minoritária do Poder Público uma modalidade de subsídio ou subvenção. Saliente-se, porém, que se trata de modalidade pouco usual de participação estatal nas atividades empresariais.

A legislação brasileira não se afastou das formas usuais de participação estatal na gestão de empresas industriais e comerciais.

A Reforma Administrativa, após desdobrar a Administração Federal em Direta e Indireta, esclareceu que esta compreenderia três categorias de entidades, com personalidade jurídica própria: autarquias, empresas públicas e sociedades de economia mista. Definiu ainda cada uma dessas categoria, esclarecendo ser:

"I - Autarquia - o serviço autônomo, criado por lei, com personalidade jurídica, patrimônio e receita próprios, para executar atividades típicas da Administração Pública, que requeiram, para seu melhor funcionamento, gestão administrativa e financeira descentralizada.

II - Empresa Pública - a entidade dotada de personalidade jurídica de direito privado, com patrimônio próprio e capital exclusivo da União, criada por lei para a exploração de atividade econômica que o Governo seja levado a exercer por força de contingência ou de conveniência administrativa, podendo revestir-se de qualquer das formas admitidas em direito.

III - Sociedade de Economia Mista - a entidade dotada de personalidade jurídica de direito privado, criada por lei para a exploração de atividade econômica, sob a forma de sociedade anônima, cujas ações com direito a voto pertençam em sua maioria à União ou a entidade da Administração Indireta". ${ }^{2}$

O Estado Brasileiro exerce, portanto, atividades econômicas, por intermédio da Administração Direta (departamentos e serviços integrados nos diversos ministérios) e da Administração Indireta: autarquias, empresas públicas e sociedades de economia mista. A Constituição Federal de 24 de janeiro de

(2) Decreto-lei n. 200 , de 25 de fevereiro de 1967, artigo $5 .{ }^{\circ}$

R. Serv. públ., Brasilia, 108 (3) set./dez. 1973 
1967, em seu artigo $170, \S 2 .^{\circ}$, declara expressamente a preferência pelas empresas públicas e sociedades de economia mista, como a modalidade jurídica adequada para a exploração de atividade econômica pelo Estado.

Após definido o quadro teórico, jurídico e organizacional dentro do qual o Estado Brasileiro exerce atividades de caráter comercial e industrial, entremos na análise da fórmula adequada para que tais atividades fiquem sujeitas a controle $\mathrm{fi}$ nanceiro.

Esclareça-se, em primeiro lugar, que o problema do controle financeiro na área da Administração Pública sofreu e continua sofrendo profunda transformação. Esse controle, em sua origem e na teoria clássica, tinha a dupla finalidade de assegurar ao Parlamento o exercício de uma fiscalização efetiva sobre a execução do orçamento por ele aprovado, e de assegurar, também, a honestidade dos agentes da Administração responsáveis pela arrecadação, guarda e aplicação de dinheiros públicos.

Esse sistema clássico de controle financeiro ajustava-se à concepção do Estado liberal e não intervencionista, ao qual eram vedadas incursões na área econômica e deveria limitar seus gastos e, conseqüentemente, suas receitas, ao mínimo indispensável para o exercício das funções tradicionais de defesa, segurança, justiça e execução de obras e empreendimentos desinteressantes para a iniciativa privada. Colocado o Parlamento na função de defensor da bolsa do contribuinte contra os excessos fiscais do Executivo e limitado este em suas funções pelas dotações do Orçamento, o controle financeiro seria exercido com rigor para impedir o desrespeito a essas limitações.

Impossibilitado, por sua própria composição como colégio político, de exercer em detalhe e permanentemente o controle financeiro do Executivo, criaram os Parlamentos órgãos especializados e independentes, sob a forma de Departamentos de Auditoria e Fiscalização ou de Tribunais e Cortes de Contas, para o exercício dessas funções.

O problema tornou-se muito mais complexo nos tempos modernos, impossibilitando soluções dentro da filosofia e da sistemática do liberalismo econômico. O Estado passou a exercer atividades econômicas, a funcionar como produtor de mercadorias e serviços e a se responsabilizar pelo crescimento equilibrado da economia, pleno emprego dos fatores disponiveis 
e distribuição equitativa da renda. Os Parlamentos esqueceramse de sua função de defensores da bolsa do contribuinte contra a voracidade fiscal do Executivo e, premidos pelos grupos de pressão e pela crescente participação nos órgãos legislativos dos partidos populistas e associações representativas de classes e de grupos, enveredaram pelo caminho do aumento dos gastos públicos, que passaram a ser freados pelo Executivo, responsável pelo saneamento da moeda e bom funcionamento do sistema financeiro.

A intervenção do Estado no domínio econômico deu, ainda, caráter altamente técnico a muitos órgãos governamentais, às suas operações financeiras e às despesas por eles realizadas. Como poderia uma Assembléia Parlamentar ou um organismo de controle puramente fiscal, pronunciar-se com propriedade sobre operações de uma usina nuclear, uma usina siderúrgica, O problema transformou um organismo de pesquis nã espaciais? ficar a conformidade de gastos e operações financeiras com uma discriminação aprovada pelo Parlamento, mas, acima de tudo, apurar se o Governo executava, com propriedade técnica e eficiência, operações de caráter econômico cuja responsabilidade havia assumido. O controle orçamentário puramente formal, através do exame da legalidade de operaçổes financeiras executadas pelo Governo, cedeu lugar a análises mais requintadas como a de custo-benefício e outras da mesma natureza. A solução encontrada foi de compromisso. O respeito às
instituições parlamentares e ao sistema democrático (o pior sistema na opinião de Churchill, com exceção de todos os demais) exigiu que se reconhecesse ao Parlamento o que um escritor
italiano denominou de "direito especial de vigilância sobre as operações financeiras do Governo". Manteve-se o princípio da aprovação, pelo Parlamento, da lei orçamentária, com limitade despesas, de emendas e de aprovação de gastos sem receitas para sua cobertura. As técnicas do orçamento-programa, dos orçamentos plurianuais e dos orçamentos de investimentos foram implantadas para assegurar a continuidade e a estabilidade dos programas governamentais.

A Inglaterra, origem das instituições parlamentares e do país a adaptar instituições tradicionais aos tempos modernos. A votação da lei orçamentária pelo Parlamento é hoje puramente formal, pelo menos no tocante à aprovação das despesas. 
Só o Governo possui a iniciativa de despesas, vedada ao Parlamento a apresentação de emendas que aumentem os gastos propostos pela Coroa. As vinte sessões (supply days) reservadas para a discussão e votação das despesas incluídas na proposta orçamentária são utilizadas para debates políticos de caráter geral. No fim, o Governo usa o processo da guilhotina, pedido de aprovação em bloco das despesas constantes da proposta, cuja recusa importará em moção de desconfiança, queda do Gabinete, dissolução do Parlamento e convocação de eleições gerais.

Essa transformação na posição dos Parlamentos como órgãos de controle financeiro não poderia deixar de se refletir nas funções dos órgãos que, como delegados do Legislativo, devem acompanhar e fiscalizar a execução orçamentária. $\mathrm{O}$ sistema do controle prévio, segundo o qual nenhuma despesa pública poderia ser realizada sem o prévio pronunciamento do órgão de controle, não pôde subsistir, pois seria e é inexequível face ao vulto das despesas em um Estado Moderno, à sua complexidade e à celeridade e flexibilidade exigidas da Administração quando exerce funções e realiza operações de caráter econômico.

Tivemos ocasião de acompanhar de perto, na Inglaterra, o problema surgido no pós-guerra, quando o Governo Trabalhista socializou importantes setores da economia do país: minas de carvão, transportes, geração de energia e siderurgia, criando grandes empresas públicas (public corporations) para a sua exploração. As leis que criaram essas empresas determinaram que as mesmas mantivessem contabilidade adequada, sujeita a auditoria de contabilistas comerciais aprovados como auditores. Deveriam ainda essas empresas submeter as suas contas, devidamente auditadas, e um relatório anual ao Ministro a que estivessem jurisdicionadas, o qual encaminharia esses documentos ao Parlamento. Por ocasião da discussão da lei que socializou a indústria carbonífera, foi apresentada emenda dando poderes ao Controlador e Auditor-Geral para examinar as contas das corporações públicas e certificá-las antes de sua apresentação ao Parlamento. A emenda foi rejeitada pelo Governo, sob o fundamento da existência do risco de interferirem nas atividades correntes da corporação, e que o Comitê de Contas Públicas do Parlamento dispunha de poderes para convocar pessoas e requisitar documentos e registros quando julgasse necessário. Na época estávamos fazendo um estágio no Departamento do Auditor e Controlador-Geral e verificamos 
que a opinião reinante no Departamento era contra a aprovação da emenda, sob o fundamento de que o mesmo não dispunha de meios nem estava tecnicamente capacitado para exercer uma auditoria eficaz das contas das corporações, e que a meIhor solução seria realmente deixar essa auditoria a cargo de firmas especializadas particulares de auditores, de alta idoneidade técnica e moral, que já exerciam tais funções em grandes firmas e empresas privadas. ${ }^{3}$

Após esta exposição, creio que podem ser apresentadas algumas conclusões que, sem pretenderem esgotar o problema, podem contribuir para melhor esclarecimento do assunto e 0 encontro de soluções adequadas.

PRIMEIRA CONCLUSÃO - Quando o Estado explora atividades de caráter comercial ou industrial através da administração direta, ou seja de departamentos e serviços integrantes da Administração Centralizada, essas atividades e as operações financeiras delas resultantes estão sujeitas a controle e fiscalização financeira de rotina. Não haverá no caso qualquer obstáculo ou prejuízo para a eficiência dos trabalhos, pois se o próprio Estado não considerou necessária a concessão de autonomia administrativa e financeira a esses serviços é porque considera ser possivel o seu funcionamento dentro das normas e sistemas comuns da administração. SEGUNDA CONCLUSÃO - Se para a execução da ativi-
dade industrial e comercial foi criada uma autarquia administrativa, ou seja um serviço público descentralizado, com personalidade jurídica e autonomia administrativa e financeira, o controle financeiro a que estará sujeita a autarquia será aquele estabelecido para entidades desse tipo. A Constituição Federal estabelece expressamente que as normas de fiscalização financeira e orçamentária contidas na Seção VII do Capítulo VI aplicam-se às autarquias, que ficam portanto sujeitas à apreciação e julgamento, pelo Tribunal de Contas da União, das suas contas e das contas dos responsáveis pela sua administração.

TERCEIRA CONCLUSÃO - As empresas públicas e as sociedades de economia mista, nos termos do artigo $170, \S 2 .^{\circ}$, da Constituição Federal, deverão reger-se pelas normas apli-
cáveis às empresas privadas, inclusive quanto ao direito do
trabalo trabalho e ao das obrigações. O parágrafo único do artigo 27 da

(3) Há uma interessante exposição do assunto no excelente livro: "The Control of Public Expenditures". da autoria de Basil Chubb, Oxford, Clarendon Press, 1952. Sobre o mesmo assunto merece consulta o folheto: "Accountability to Parliament", publicado Dela "Acton Society Trust", de Londres, em 1950. 
lei da Reforma Administrativa já dispusera que seriam asseguradas, às empresas públicas e às sociedades de economia mista, condições de funcionamento idênticas às do setor privado, cabendo a essas entidades, sob a supervisão ministerial, ajustar-se ao plano geral do Governo. O sistema de controle financeiro a que estão sujeitas as empresas públicas e as sociedades de economia mista deve ser, portanto, o mesmo estabelecido para as sociedades anônimas de direito privado. Deverão elas ter, portanto, obrigatoriamente, um Conselho Fiscal, cuja composição, forma de eleição, duração do mandato, funções e responsabilidades, são fixadas na lei das sociedades por ações (decreto-lei n. 2.627 , de 26 de setembro de 1940). É generalizada a crítica à pouca eficiência da função fiscalizadora exercida nas sociedades anônimas pelos conselhos fiscais, acusados de se limitarem, na maioria das vezes, a referendar com sua assinatura os balanços apresentados pelas Diretorias das empresas. É de se salientar, porém, que no caso das empresas públicas e das sociedades de economia mista, a União Federal, pela sua situação majoritária na Assembléia Geral dos Acionistas, escolhe e elege os membros do Conselho Fiscal, ou pelo menos a sua maioria. Cabe, portanto, ao Poder Público fazer com que essa escolha recaia sobre pessoas não só moralmente idôneas, como tecnicamente competentes para a função. Deve também a Administração exigir dos conselheiros eleitos estrita e rigorosa observância de suas funções, obrigações e responsabilidades legais, inclusive remunerando-os adequadamente. Aliás, um dos pontos importantes a serem cogitados na reforma da lei de sociedades por ações, reforma esta cuja oportunidade e urgência é sentida por todos, é dar maior relevância e responsabilidade às funções do Conselho Fiscal, disciplinando-as e regulamentando-as.

Papel importante é hoje reservado à auditoria contábil especializada, a cargo de firmas e profissionais independentes, como um dos meios mais adequados para assegurar um controle externo eficiente sobre as contas das grandes empresas, controladas pelo capital privado ou pelo Poder Público. Uma série de normas disciplina hoje no Brasil a atuação dessas firmas e desses profissionais, os quais devem se inscrever, obrigatoriamente, nos Conselhos Regionais de Contabilidade, na forma estabelecida pela Resolução n. 317 , de 14 de janeiro de 1972, do Conselho Federal de Contabilidade.

O Banco Central do Brasil, a fim de exercer com eficiência a função fiscalizadora que a lei lhe atribuiu, não só sobre as

R. Serv. públ., Brasília, 108 (3) set./dez. 1973 
instituições financeiras como também sobre as empresas, privadas e públicas, emissoras de títulos e valores mobiliários negociáveis em bolsas de valores, tem-se preocupado com o assunto, baixando normas disciplinadoras da ação das firmas de auditoria e auditores independentes. Entre essas normas cabe destacar a Resolução $n .^{\circ} 220$, de 10 de maio de 1972, que estabelece condições para a auditoria dos demonstrativos contábeis das pessoas jurídicas de direito privado, inclusive sociedades de economia mista, obrigadas a registro no Banco Central do Brasil, como emissoras de títulos e valores mobiliários negociáveis em bolsas de valores. Nos termos dessa Resolução é obrigatória a auditoria, por auditores contábeis independentes, registrados no Banco Central, do balanço geral, da demonstração do resultado do exercício, do demonstrativo de lucros e perdas ou prejuízos em suspenso e notas explicativas da diretoria. A Circular $\mathrm{n} .^{\circ} 178$, de 11 de maio de 1972 , do mesmo Banco Central do Brasil, baixou normas relativas ao registro de auditores independentes naquele Banco; e a Circular $n .^{\circ} 179$, da mesma data, aprovou as Normas Gerais de Auditoria e disciplinou os Princípios e Normas de Contabilidade, aplicáveis às empresas industriais e comerciais.

Já está portanto instituído, entre nós, um sistema de controle financeiro aplicável à grande maioria das sociedades de economia mista da União, pois vigora para as instituições financeiras públicas (Banco do Brasil S.A., Banco Nacional da Habitação, Caixa Econômica Federal, Banco Nacional do Desenvolvimento Econômico, Banco do Nordeste do Brasil S.A. e outras) e para as empresas emissoras de títulos negociáveis em bolsa (Petrobrás, Cia. Vale do Rio Doce, Cia. Siderúrgica Nacional e outras). Nada impede que o sistema da auditoria independente seja obrigatoriamente estendido a todas as empresas públicas e sociedades de economia mista. Finalmente, como o ato final do controle financeiro externo é a aprovação ou desaprovação, pelo Congresso Nacional, das contas do Poder Executivo, seria de se desejar que a lei tornasse obrigatória a anexação, à pres. tação de contas do Presidente da República (artigo 70 da Constituição Federal), submetida ao parecer prévio do Tribunal de Contas da União, dos balanços gerais e demonstração de lucros e perdas das empresas públicas e sociedades de economia mista, acompanhados dos relatórios de suas Diretorias e da apreciação de auditoria indèpendente. Seria então a oportunidade, para o Tribunal de Contas da União estender sua apreciação a essas contas e o Congresso Nacional delas tomar conhecimento, discuti-las e apreciá-las. 


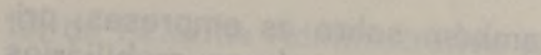

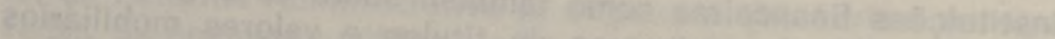

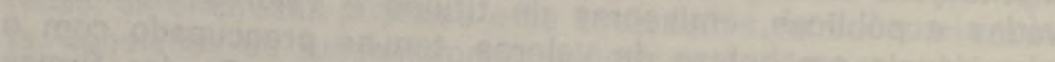
Wanch

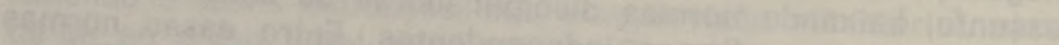

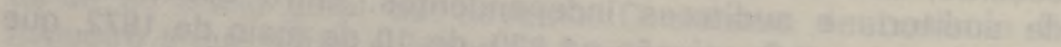

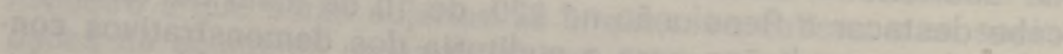

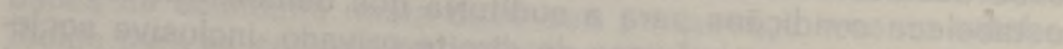

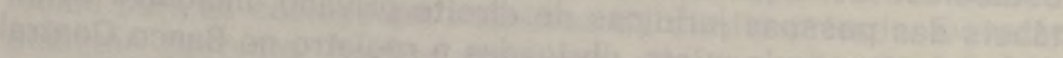

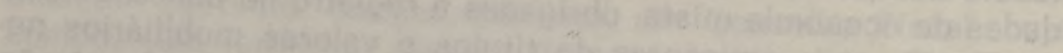

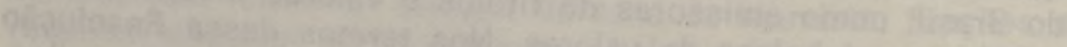

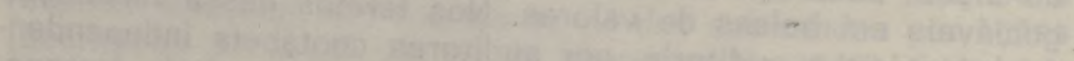

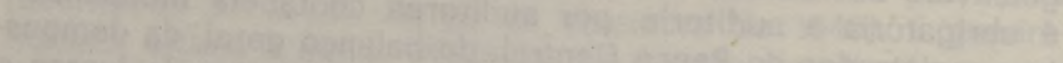

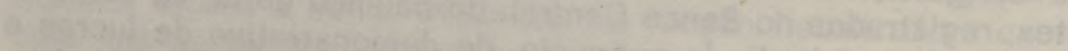

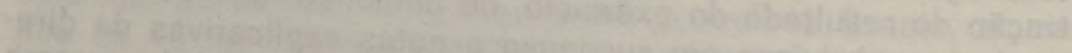

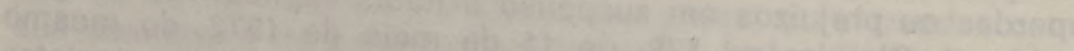

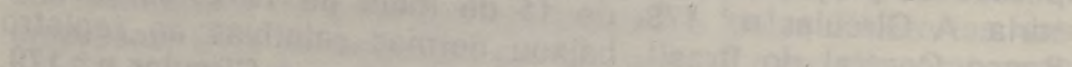

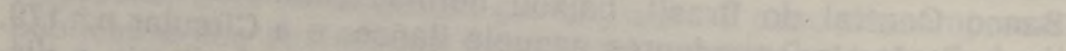

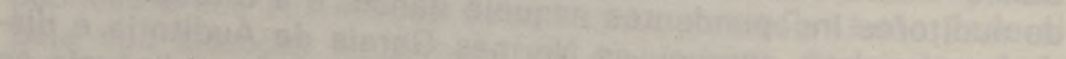

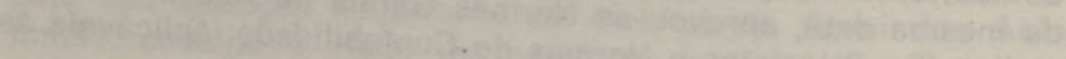

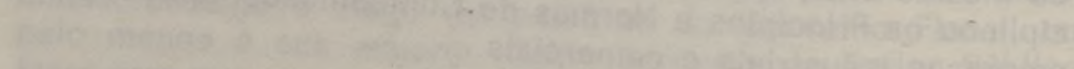

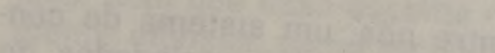
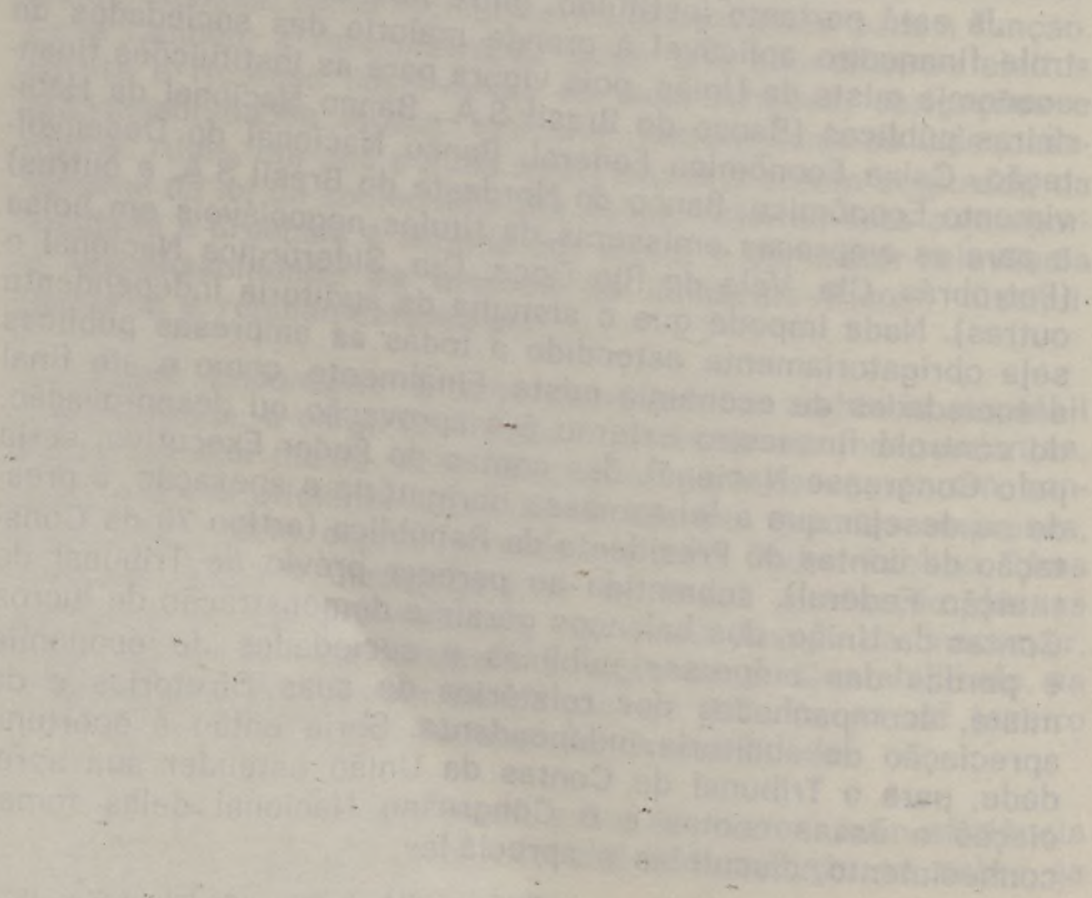